Fabrication and interfacing of nanochannel devices for single-molecule studies

This article has been downloaded from IOPscience. Please scroll down to see the full text article.

2009 J. Micromech. Microeng. 19065017

(http://iopscience.iop.org/0960-1317/19/6/065017)

The Table of Contents and more related content is available

Download details:

IP Address: 130.89.19.12

The article was downloaded on 30/09/2009 at 09:22

Please note that terms and conditions apply. 


\title{
Fabrication and interfacing of nanochannel devices for single-molecule studies
}

\author{
H T Hoang ${ }^{1}$, I M Segers-Nolten ${ }^{2}$, J W Berenschot ${ }^{1}$, M J de Boer ${ }^{1}$, \\ N R Tas ${ }^{1}$, J Haneveld ${ }^{1}$ and M C Elwenspoek ${ }^{1,3}$ \\ ${ }^{1}$ Transducers Science and Technology Group, MESA ${ }^{+}$Research Institute for Nanotechnology, \\ University of Twente, PO Box 217, 7500 AE Enschede, The Netherlands \\ ${ }^{2}$ Biophysical Engineering Group, Institute for Biomedical Technology and MESA ${ }^{+}$Research Institute \\ for Nanotechnology, University of Twente, PO Box 217, 7500 AE, Enschede, The Netherlands \\ ${ }^{3}$ Freiburg Institute for Advanced Studies (FRIAS), University of Freiburg, Albertstrasse 19, \\ D-79194 Freiburg, Germany \\ E-mail: t.h.hoang@ewi.utwente.nl
}

Received 18 February 2009, in final form 14 April 2009

Published 20 May 2009

Online at stacks.iop.org/JMM/19/065017

\begin{abstract}
Nanochannel devices have been fabricated using standard micromachining techniques such as optical lithography, deposition and etching. 1D nanochannels with thin glass capping and through-wafer inlet/outlet ports were constructed. 2D nanochannels have been made transparent by oxidation of polysilicon channel wall for optical detection and these fragile channels were successfully connected to macro inlet ports. The interfacing from the macro world to the nanochannels was especially designed for optical observation of filling liquid inside nanochannels using an inverted microscope. Toward single-molecule studies, individual quantum dots were visualized in $150 \mathrm{~nm}$ height $1 \mathrm{D}$ nanochannels. The potential of 2D nanochannels for single-molecule studies was shown from a filling experiment with a fluorescent dye solution.
\end{abstract}

M This article features online multimedia enhancements

(Some figures in this article are in colour only in the electronic version)

\section{Introduction}

Recently, several single-molecule studies using nanochannels have been reported. For instance, single DNA fragments were confined and detected in $500 \mathrm{~nm}$ diameter silica capillaries [1]. Interactions of single DNA and protein molecules were studied in $120 \mathrm{~nm} \times 150 \mathrm{~nm}$ fused silica channels [2]. Single rhodamine labeled cellulase enzyme was detected in $100 \mathrm{~nm}$ diameter glass nanochannels [3]. In single-molecule studies, individual molecules need to be distinguished and identified. Discrimination of single molecules [4] can simply be achieved by preparing extremely dilute solutions, containing in average only one molecule per detection volume. However, for biological applications this is undesirable because usually biomolecules are only functional at much higher concentrations, similar to those present in a cellular environment [5]. Moreover, by extreme dilution the contribution of background signals from solvent molecules relative to the signals of the molecules of interest is enhanced. Another approach is to enable single-molecule studies by reduction of the detection volume. The detection volume can significantly be reduced by optical methods such as confocal fluorescence microscopy using small pinholes to minimize the detection of out-of-focus light [6]. Total internal reflection fluorescence microscopy (TIRFM) can also be used, where excitation only takes place in a limited field formed by evanescent waves [7]. Another option would be near-field scanning optical microscopy (NSOM) [8], where the detection volume is determined by the narrow aperture of an optical fiber probe. These optical techniques provide a detection depth as small as $100 \mathrm{~nm}$. If nanochannels are used for sample confinement, the channel height can be reduced even further 
Table 1. Overview of 1D nanochannel fabrication methods.

\begin{tabular}{|c|c|c|c|c|}
\hline Nanochannel pattern & Materials & Etching/Deposition & Height & References \\
\hline Optical lithography & Silicon & OPD solution, $\mathrm{HF}: \mathrm{NH}_{4} \mathrm{~F}: \mathrm{H}_{2} \mathrm{O}$ & $50 \mathrm{~nm}$ & {$[25-28]$} \\
\hline Optical lithography & Silicon & BHF etching of $\mathrm{SiO}_{2}+$ local oxidation & $70 \mathrm{~nm}$ & [29] \\
\hline Optical lithography & Silicon & RIE & $90 \mathrm{~nm}$ & [30] \\
\hline Optical lithography & $\mathrm{SiO}_{2}$, amorphous $\mathrm{Si}$ & BHF solution & $150 \mathrm{~nm}$ & [31], this work \\
\hline Optical lithography & $\mathrm{SiO}_{2}$ & $\mathrm{BHF}+$ double thermal oxidation & $75 \mathrm{~nm}$ & {$[9]$} \\
\hline $\mathrm{EBL}$ & Silica & $\mathrm{RIE}\left(\mathrm{CHF}_{3} / \mathrm{O}_{2}\right)$ & $70 \mathrm{~nm}$ & [32] \\
\hline Optical lithography & Fused silica & RIE & $40 \mathrm{~nm}$ & {$[33,34]$} \\
\hline Optical lithography & Silicon, glass & $\begin{array}{l}\text { RIE for silicon } \\
\text { BOE for glass }\end{array}$ & $20 \mathrm{~nm}$ & {$[35,36]$} \\
\hline Optical lithography & Pyrex & $\mathrm{BHF}$ & $6 \mathrm{~nm}$ & {$[37]$} \\
\hline
\end{tabular}

Table 2. Overview of 2D nanochannel fabrication methods.

\begin{tabular}{|c|c|c|c|c|}
\hline Nanochannel pattern & Materials & Etching/Deposition & Dimensions & References \\
\hline FIB & $\begin{array}{l}\text { Silicon }(\mathrm{SiN}) \text {, glass, } \\
\quad \text { quartz, fused silica }\end{array}$ & FIB & $50 \mathrm{~nm} \times 50 \mathrm{~nm}$ & {$[2,12,13]$} \\
\hline EBL & $\begin{array}{l}\text { Silicon }\left(\mathrm{SiO}_{2}, \mathrm{SiN}\right) \\
\quad \text { fused silica }\end{array}$ & $\begin{array}{l}\mathrm{RIE}\left(\mathrm{CHF}_{3} / \mathrm{O}_{2},\right. \\
\left.\mathrm{CF}_{4}: \mathrm{CHF}_{3}\right)\end{array}$ & $50 \mathrm{~nm} \times 50 \mathrm{~nm}$ & {$[14-16]$} \\
\hline NIL & Silicon (oxide), fused silica & $\operatorname{RIE}\left(\mathrm{CHF}_{3} / \mathrm{O}_{2}\right)$ & $10 \mathrm{~nm} \times 50 \mathrm{~nm}$ & [17-19] \\
\hline NIL+ diffraction gradient lithography & Silicon & $\operatorname{RIE}\left(\mathrm{CHF}_{3} / \mathrm{O}_{2}\right)$ & $10 \mathrm{~nm} \times 50 \mathrm{~nm}$ & {$[38]$} \\
\hline Interferometic lithography & Silicon & $\operatorname{RIE}\left(\mathrm{CHF}_{3} / \mathrm{O}_{2}\right)$ & $\begin{array}{l}100 \mathrm{~nm} \text { width \& } \\
500 \mathrm{~nm} \text { height }\end{array}$ & {$[39]$} \\
\hline Sacrificial etching & Silicon, silicon oxide, polymer & (B)HF, RIE, heating & $\begin{array}{l}30 \mathrm{~nm} \text { height \& } \\
200 \mathrm{~nm} \text { width }\end{array}$ & {$[3,40]$, this work } \\
\hline Local oxidation & Silicon oxide & $\mathrm{RIE}\left(\mathrm{CH}_{4}\right)$ & $150 \mathrm{~nm} \times 200 \mathrm{~nm}$ & [41] \\
\hline Electrochemistry & Silicon & $\mathrm{KOH}$ & $30 \mathrm{~nm}$ diameter & [20] \\
\hline Scanned coaxial electrospinning & Silica & Deposition & $20 \mathrm{~nm}$ diameter & {$[21]$} \\
\hline $\begin{array}{l}\text { Thermo mechanical deformation \& } \\
\mathrm{CO}_{2} \text { laser based puller }\end{array}$ & Polymer \& silica glass capillaries & Pulling & $400 \mathrm{~nm}$ diameter & {$[22,23]$} \\
\hline Chemical mechanical polishing & Silicon oxide & $\mathrm{BOE}$ & $\begin{array}{l}25 \mathrm{~nm} \text { wide \& } \\
100 \mathrm{~nm} \text { height }\end{array}$ & {$[24]$} \\
\hline Nonconformal deposition & Polymer & Deposition & $100 \mathrm{~nm}$ size & [42] \\
\hline
\end{tabular}

toward detection depths as small as $5 \mathrm{~nm}[9,10]$. As said, the ultra small detection volume of nanochannels enables single-molecule experiments at relatively high concentrations. Furthermore, carrying out single-molecule experiments in nanochannels does not require immobilization of molecules and offers the possibility of exactly controlling and manipulating the sample conditions. In addition, the benefits of nanochannel devices may be exploited for high-throughput applications.

Nanochannels can be relatively easily fabricated using bulk, surface, mold and bond micromachining techniques [43]. Using bulk and bond machining, nanochannels are created by etching trenches in a substrate that are closed by bonding to another substrate [25, 36]. Surface channels can be formed on a substrate with deposited layers (sacrificial and structural layers) after selectively etching of the sacrificial layer [44, 45]. In mold/bond machining, a mold formed on a substrate is filled by a desired layer, and then the mold is removed to release channels which are closed by bonding the replica to another substrate (for a detailed review [11]). 1D nanochannels are created by etching shallow trenches after standard lithography, while 2D nanochannel patterns are generally obtained using nanolithographic techniques such as focused ion beam (FIB) lithography [2, 12, 13], electron beam lithography (EBL) [14-16] and nanoimprint lithography (NIL) [17-19]. Although nanochannels with two dimensions down to $10 \mathrm{~nm}$ have been successfully fabricated with nanolithography techniques, drawbacks are the high costs, low throughput and pattern limitations. Alternatively, other techniques such as electrochemistry [20], electrospinning [21], mechanical deformation [22, 23] and chemical mechanical polishing [24] are also employed for 2D nanochannel fabrications. The latter techniques however have drawbacks such as precisely controlling channel sizes and integration with other fluidic components. Tables 1 and 2 give an overview of various methods applied for the construction of nanochannels.

In this work, we show that $150 \mathrm{~nm}$ height $1 \mathrm{D}$ nanochannels, created using the silicon oxide spacer layer method [46], can be bonded to blank thin glass wafers with suitable thickness for using high numerical aperture (NA) lenses. Fluidic filling holes for the 1D nanochannels were created on silicon wafers with nanochannel structures to enable optical observation using a microscope with inverted configuration. Without using expensive nanolithography, but by a combination of standard micromachining techniques such as optical lithography, deposition and selective etching, 2D nanochannels were created with well-controlled dimensions of $50 \mathrm{~nm}$ height and $400 \mathrm{~nm}$ width. Fabricated 2D nanochannels were integrated with inlet ports and made transparent for 


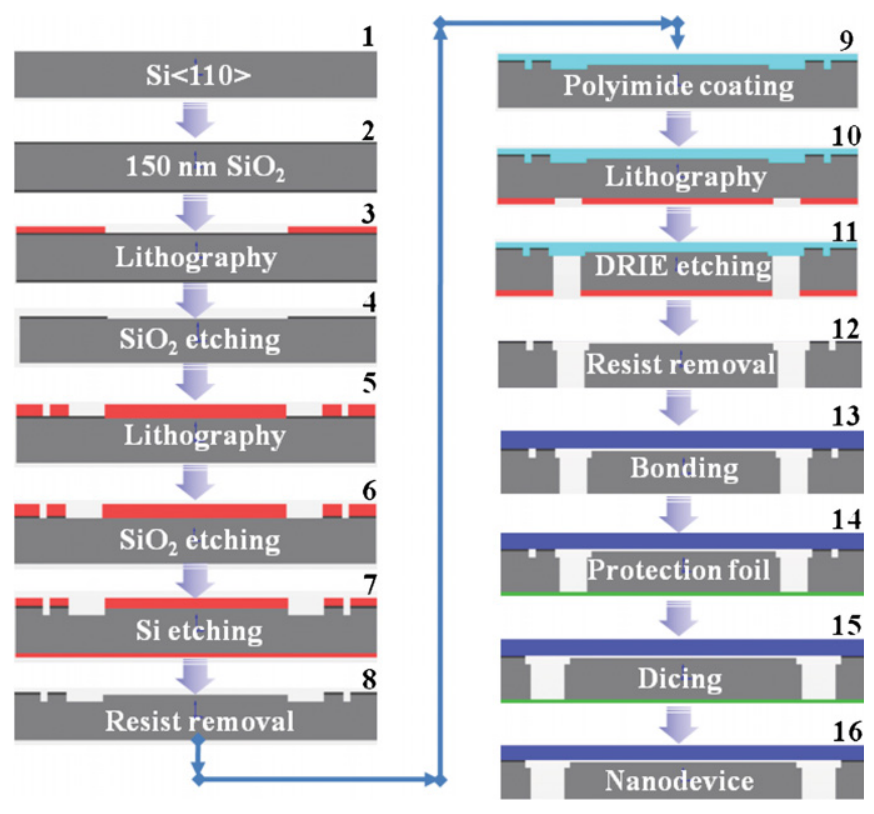

Figure 1. Process outline for fabrication of 1D nanochannel devices.

optical detection by oxidizing the polysilicon channel wall. Deep reactive ion etching (DRIE) was used to fabricate inlet/outlet ports for 1D and 2D nanochannels. Toward single molecule applications individual quantum dots in a $12 \mathrm{nM}$ concentration solution were visualized in 1D nanochannels; filling and observation of 2D nanochannels with a micromolar concentration of fluorescent solutions was shown.

\section{Experimental section}

\subsection{Fabrication of $1 D$ nanochannels by wafer bonding}

Fabrication of 1D nanochannels was based on the approach of Haneveld [46] (figure 1). The process was started on a $\left\langle\begin{array}{lll}1 & 1 & 0\end{array}\right\rangle$ silicon wafer (Okmetic) with $380 \mu \mathrm{m}$ thickness and $100 \mathrm{~mm}$ diameter (step 1). First standard cleaning was applied to the wafer (10 min in fuming $(100 \%) \mathrm{HNO}_{3}, 10$ min in boiling $(69 \%) \mathrm{HNO}_{3}$ ). A $150 \mathrm{~nm}$ thick silicon oxide layer was grown by thermal dry oxidation with oxygen flow of $41 / \mathrm{min}$ at $950{ }^{\circ} \mathrm{C}$ in $7 \mathrm{~h}$ (Amtech Tempress Omega Junior, step 2). The thickness of the silicon oxide was measured by an ellipsometry (Plasmos SD 2002). Nanochannel structures with a $20 \mu \mathrm{m}$ width were created by a standard lithography procedure (step 3 ) consisting of a dehydration step $\left(5 \mathrm{~min}, 120^{\circ} \mathrm{C}\right)$, spin coating of a HMDS adhesion promotor and Olin $907 / 12$ photoresist (20 s, $4000 \mathrm{rpm})$, soft-bake $\left(1 \mathrm{~min}, 95^{\circ} \mathrm{C}\right)$, exposure (3 s using a $12 \mathrm{~mW} \mathrm{~cm}^{-2}$ Electro Vision exposure apparatus (EVG 620)), post-exposure bake $\left(1 \mathrm{~min}, 120^{\circ} \mathrm{C}\right)$ and development $(1 \mathrm{~min}$ in an OPD 4262 developer). The structures were transferred to the silicon oxide layer (step 4) by wet chemical etching (3 min) in a buffered hydrofluoric acid (BHF) solution (Merck). Using this silicon oxide spacer layer method [46], the channel height was controlled by the thickness of the silicon oxide layer and by the time to completely etch this layer. For silicon oxide etching, BHF or $1 \%$ HF solutions can be used. In the case of channel heights larger than $50 \mathrm{~nm}$, the BHF solution is preferred because of its 'resist friendly' properties. However, BHF also etches silicon, although only at a very low rate [10]. Therefore, if the channel heights are below $20 \mathrm{~nm}$, the $1 \% \mathrm{HF}$ solution is selected due to its very high selectivity between the etch rates of silicon and silicon oxide. This means that, when using the $1 \% \mathrm{HF}$, the etching stops exactly on the silicon/silicon oxide interface, and the channel height is more precisely controlled.

To create fluidic interfacing to the nanochannels, microchannels were created on the wafer with nanochannel structures. After resist lithography (step 5), the microchannel structure was transferred to the silicon oxide layer by wet chemical etching in a BHF solution (4 min, step 6), then to the silicon layer by Reactive Ion Etching (RIE, step 7) (Oxford Plasmalab 100). The main etching parameters were a power of $600 \mathrm{~W}, 120 \mathrm{sccm} \mathrm{SF}_{6}$ flow, $-110{ }^{\circ} \mathrm{C}$ substrate temperature, $10 \mathrm{mTorr}$ process pressure and a time of $40 \mathrm{~s}$ for $2 \mu \mathrm{m}$ depth. Next, the resist was removed (step 8) for further processing. For use on an inverted microscope (figure 2(a)), inlet ports were also fabricated on the silicon wafer from the backside, connected to the microchannels (details of inlet-hole fabrication in part 2.3).

For optimal collection of fluorescent signals, high NA water immersion lenses are commonly used, optically corrected for use with $170 \mu \mathrm{m}$ thick cover glasses. Therefore we covered the 1D-nanochannels by bonding them to special, $170 \mu \mathrm{m}$ thin, blank glass wafers (Borofloat, Mark Optics). Hence, using an inverted microscope, observation of the nanochannels from the bottom and filling of the channels through inlet ports from the top was possible. Before bonding, the channel height was measured by a mechanical surface profiler (Veeco Dektak 8). Both wafers were cleaned by standard cleaning and Piranha cleaning $\left(20 \mathrm{~min}, 120{ }^{\circ} \mathrm{C}\right.$, solution of $\mathrm{H}_{2} \mathrm{SO}_{4}: \mathrm{H}_{2} \mathrm{O}_{2}=3: 1$ ) to obtain clean hydroxylated surfaces before fusion bonding. The final cleaning step was extremely difficult because the thin glass wafer is very fragile. The cleaning was performed in a rinsing bath in which water flow-up and nitrogen bubbles could be reduced. For drying a spinner at low speed or a nitrogen spray gun was used. Broad plastic tip tweezers were preferred to handle this thin wafer.

The silicon wafer with all structures was directly bonded to the blank thin glass wafer (step 13). Then the bonded wafers were annealed in a Nabertherm C 250 furnace with a program controller $\left(4 \mathrm{~h}, 400{ }^{\circ} \mathrm{C}\right)$ to enhance the bond between the silicon and the glass wafer. The bonded wafer was diced (step 15) into smaller sized chips with a protection step (step 14).

\subsection{Fabrication of transparent surface $2 D$ nanochannels}

2.2.1. Channel fabrication. In this work, we adapted and extended our previously reported surface-micromachining procedure to create transparent 2D nanochannels [43]. Figure 3 shows a brief process flow to realize the nanochannels. A starting substrate is a $\left\langle\begin{array}{lllll}1 & 0 & 0\end{array}\right\rangle$ silicon wafer with a $525 \mu \mathrm{m}$ thickness (step 1). The wafer is thermally dry oxidized $\left(4 \mathrm{l} / \mathrm{min} \mathrm{O}_{2}\right.$ flow, $\left.950{ }^{\circ} \mathrm{C}, 2 \mathrm{~h}\right)$ to realize a $50 \mathrm{~nm}$ silicon oxide sacrificial layer (step 2). Afterward, a standard 


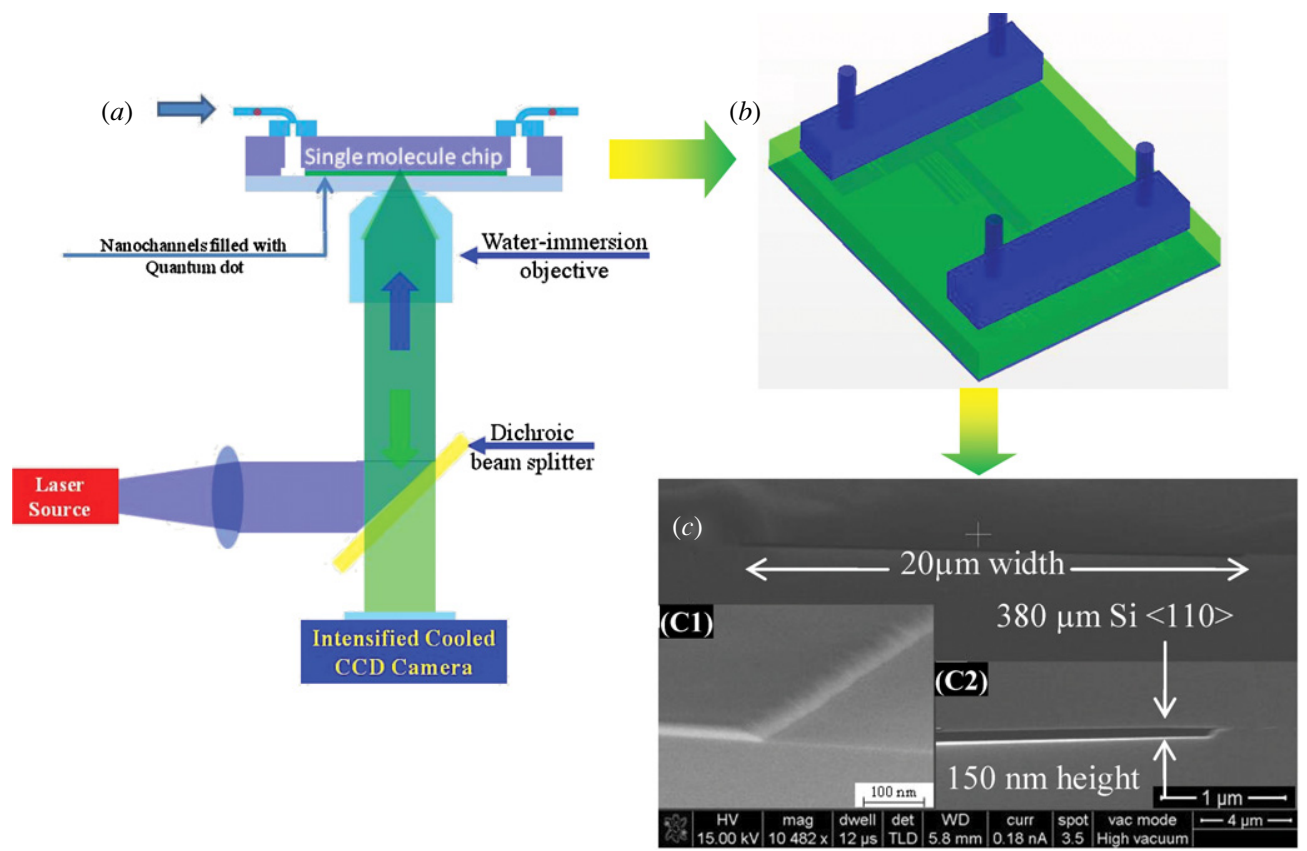

Figure 2. (a) Schematic of the experimental setup. (b) An artist drawing of a 1D nanochannel device. (c) SEM cross section of a $20 \mu \mathrm{m}$ width nanochannel bonded between a silicon wafer and a thin glass wafer. Inset C1: channel wall morphology of the nanochannel formed by wet chemical etching. Inset C2: SEM cross section of a $150 \mathrm{~nm}$ height nanochannel.

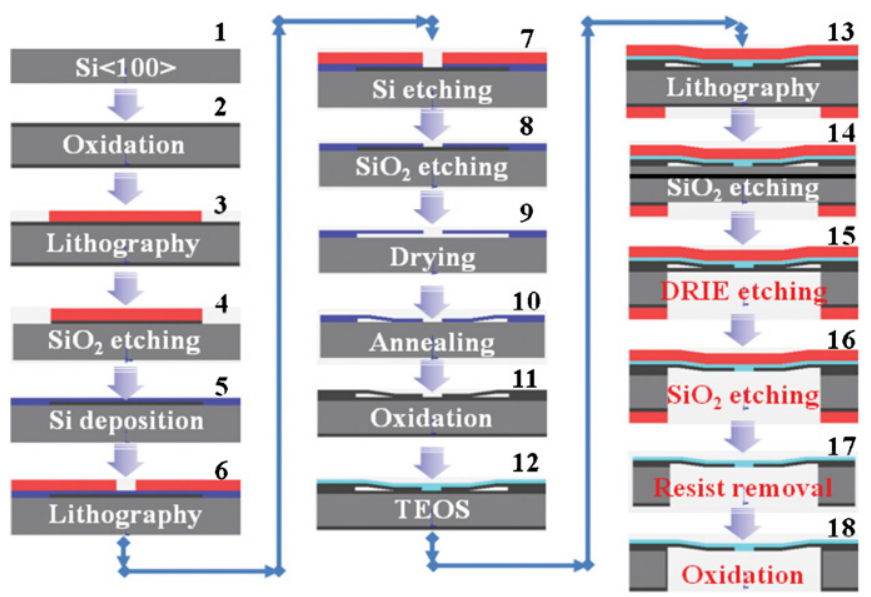

Figure 3. Process outline for fabrication of 2D nanochannel devices.

optical lithography was carried out to create $14 \mu \mathrm{m}$ wide lines in an Olin 907-12 photoresist layer (step 3). Then this pattern was transferred into the silicon oxide layer by RIE etching (step 4, $5 \mathrm{~min}$ ) using a $75 \mathrm{~W}$ power, $25 \mathrm{sccm}$ $\mathrm{CHF}_{3}$ flow and 10 mTorr pressure. After photoresist stripping, the patterned oxide layer was capped by a $20 \mathrm{~nm}$ thick polysilicon layer deposited by low-pressure chemical vapor deposition (LPCVD) with $50 \mathrm{sccm} \mathrm{SiH}_{4}$ flow at $590{ }^{\circ} \mathrm{C}$ and 200 mTorr pressure in $7 \mathrm{~min}$ (Amtech Tempress Omega Junior, step 5). After a second lithographic step (6), a second RIE etching (100 W power, $30 \mathrm{sccm} \mathrm{SF}_{6}, 7 \mathrm{sccm}$ $\mathrm{CHF}_{3}, 11 \mathrm{sccm} \mathrm{O}, 100$ mTorr pressure, 2 min etching time) was carried out to open windows (step 7). Then through these windows, the sacrificial oxide layer was etched away in a $50 \% \mathrm{HF}$ solution for 2 min (step 8). The etching time was short because the sacrificial layer was removed sideward. In this etching step, the sacrificial layer was partly or completely removed to give different possibilities for the shape of the nanochannels (figure 5). Subsequently, the wafer was spin dried (step 9), and during these crucial steps, the capping polysilicon layer was pulled down and adhered to the bearing silicon substrate, thus forming closed nanochannels. Then, the wafer was thermally annealed (step 10) at $1150{ }^{\circ} \mathrm{C}$ in $\mathrm{N}_{2}$ environment ( $1 \mathrm{l} / \mathrm{min}$ flow) for $2 \mathrm{~h}$ to strengthen the bond between the polysilicon and the substrate, realizing better sealed channels. Afterward, the channels were completely oxidized (step 11) to make the capped polysilicon layer optically transparent and to create a $100 \mathrm{~nm}$ silicon oxide layer as a stop layer underneath the channels.

\subsubsection{Controlling of channel-fabrication process}

2.2.2.1. Selection of materials. 2D nanochannels were formed by adhesion of the capping layer to the substrate after removing the sacrificial layer. In sacrificial layer etching technique, silicon oxide and polysilicon layers are a common combination for sacrificial and capping layers because wet chemical etching of silicon oxide using a HF solution has high selectivity over silicon [47]. Additionally in our work, the sacrificial silicon oxide layer is preferred because of its smoothness. This leads to smooth bottom surface of the polysilicon layer which serves as the top nanochannel surface. Also, the high uniform surface of the silicon oxide layer defined the smoothness of the silicon, which forms the bottom nanochannel surface. As the nanochannels are formed by deformation and adhesion of the polysilicon film to the silicon substrate, the highly smooth surface of the used layers is a crucial factor to create strong bonding between the two materials composing the channels, creating completely sealed nanochannels. 

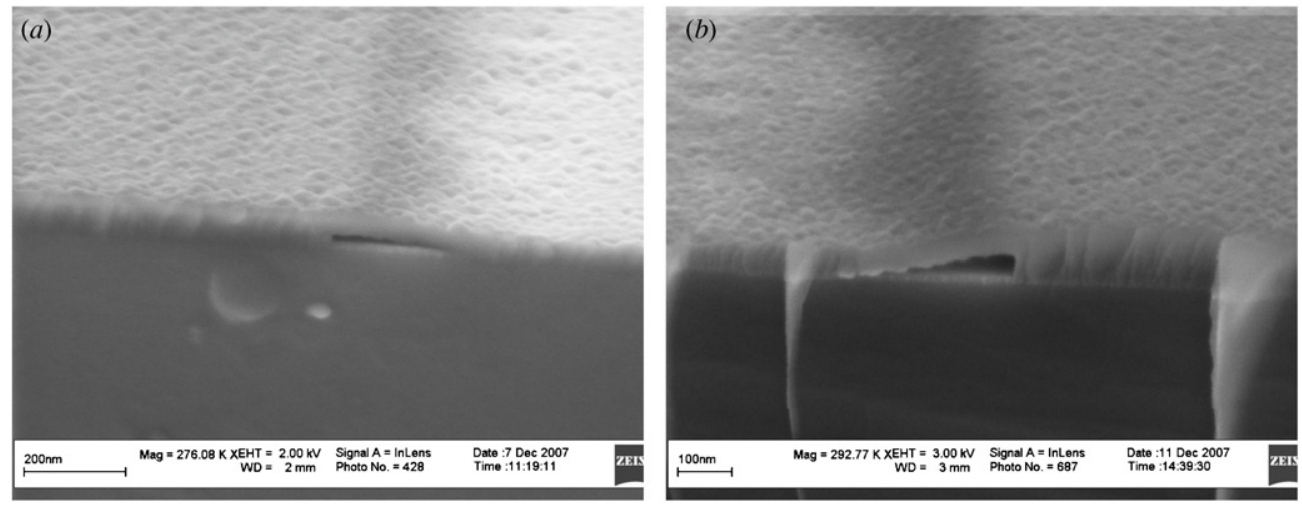

Figure 4. SEM cross-sectional images of 2D nanochannels fabricated with different thicknesses of the sacrificial layer, corresponding to the initial gap between the capping layer and the substrate of (a) $30 \mathrm{~nm}$ and (b) $50 \mathrm{~nm}$.

2.2.2.2. Channel dimensions after fabrication. Nanochannels were formed by the elastic deformation and adhering of the capping layer to the substrate after the removal of the sacrificial layer. Therefore, both the channel height and width are strongly determined by the thickness and mechanical properties of the used sacrificial and capping layers. First, the height of the channels was exactly equal to the thickness of the sacrificial layer. We observed channels with $27 \pm 3 \mathrm{~nm}$ height (figure 4(a)) and $48 \pm 3 \mathrm{~nm}$ (figure 4(b)) height, in correspondence with to the initial gap of $30 \mathrm{~nm}$ and $50 \mathrm{~nm}$ (measured by ellipsometry) between the capping layer and the substrate.

The channel width is depending on the thicknesses of both layers. Because the nanochannels were created due to deformation of the capping layer, the channel width also depends on mechanical properties of the capping layer as well as the adhesion energy of the capping layer to the substrate. The channel width $x$ is found by energy minimization [48]:

$$
x=\sqrt[4]{\frac{3}{2} \frac{E t^{3} g^{2}}{\gamma}},
$$

where $E$ is Young's modulus of the capping layer, $t$ is the thickness of the capping layer, $g$ is the thickness of the sacrificial layer, and $\gamma$ is the adhesion energy. From equation (1), one can see that the thinner layers create more narrow nanochannels. From a fabricated channel (figure 5(c)) with width $x=375 \pm 15 \mathrm{~nm}$, thickness $g=44 \pm 5 \mathrm{~nm}$, thickness $t=21 \pm 3 \mathrm{~nm}$, the adhesion energy $E=150 \mathrm{GPa}$, $\gamma$ of the bond between the capping layer and the substrate was about $0.2 \mathrm{~J} \mathrm{~m}^{-2}$, which is calculated from equation (1) and confirmed to be in the range of the adhesion energy of silicon-silicon bonds [43, 49].

\subsubsection{Preservation of channel features after post-} processes. For optical detection, transparent channels are required therefore the fabricated channels were oxidized to transform the polysilicon layer which forms channel walls to a transparent silicon oxide layer. It is desired that features of the fabricated channels such as shape and sizes are preserved after post-processes. Therefore, an investigation of the oxidation of the fabricated channels was carried out. The polysilicon capping layer was partly oxidized and figure $5(e)$ shows the capping layer with an interface (indicated by white dots) between oxidized polysilicon (14 $\pm 3 \mathrm{~nm}$ thick) and the remaining polysilicon (18 $\pm 3 \mathrm{~nm}$ thick) layers with a total thickness of $32 \pm 3 \mathrm{~nm}$. To prove this observation, the oxidized polysilicon layer was removed by $\mathrm{HF} 50 \%$ to reveal the remaining polysilicon layer $(20 \pm 3 \mathrm{~nm}$ thick in figure $5(g)$ ). Furthermore, we observed that the capping layer was pushed up due to the volume expansion during transformation of polysilicon to silicon oxide. It was indicated by an increase in channel height from $44 \pm 5 \mathrm{~nm}$ (before oxidation in figure $5(c)$ ) to $84 \pm 5 \mathrm{~nm}$ (after oxidation in figure $5(h)$ ). During oxidation, the capping polysilicon layer (from point A to point B in figures $5(c),(h)$ ) was elongated from $370 \pm 15 \mathrm{~nm}$ to $374 \pm 15 \mathrm{~nm}$. Also, the capping layer became thicker, from $21 \pm 3 \mathrm{~nm}$ to $53 \pm 3 \mathrm{~nm}$. From its thickness and length expansion, the volume ratio of the capping layer after and before oxidation was determined to be about 2.6, which is in the same range as the ratio in bulksilicon oxidation [50]. Surely, the most important observation is the oxidized polysilicon that hangs over channel areas rather than collapsing or blocking the channels, which confirms the preservation of the fabricated channels.

For integration of the fabricated nanochannels to the outer world, a thicker layer such as silicon oxide or silicon nitride was deposited on top of the channels. This layer mechanically protects for the fragile channels from damage. Figure 7(a) shows the fabricated channels with a deposited silicon oxide layer of $500 \mathrm{~nm}$ thickness without any collapse.

\subsection{Fabrication of fluidic inlet/outlet ports}

In nanochannel devices interfacing from macro inlet ports to the nanochannels is necessary for proper delivery of liquid into the nanochannels. Inlet ports can be created by different processes, such as powder blasting and DRIE etching [51]. For 1D bonded nanochannels, powder blasting is commonly selected to form inlet ports on glass wafers [25]. In order to use an inverted microscope, inlet ports formed on silicon wafers containing the nano-/micro-channel structures, DRIE etching was a preferred alternative method to avoid damage of nanochannels. Protection of the nanochannels against damage was crucial. The fabricated channels were protected by coating 


\section{Partly etched silicon oxide}

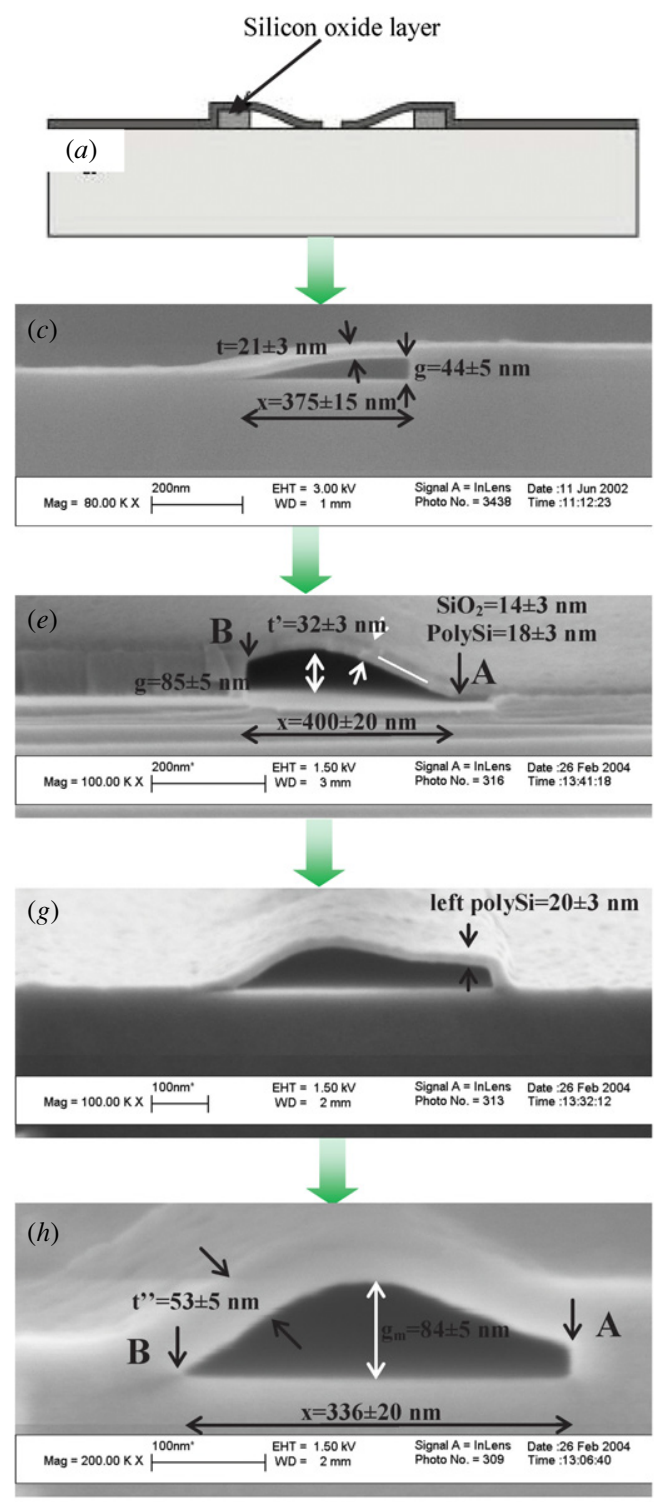

Completely etched silicon oxide
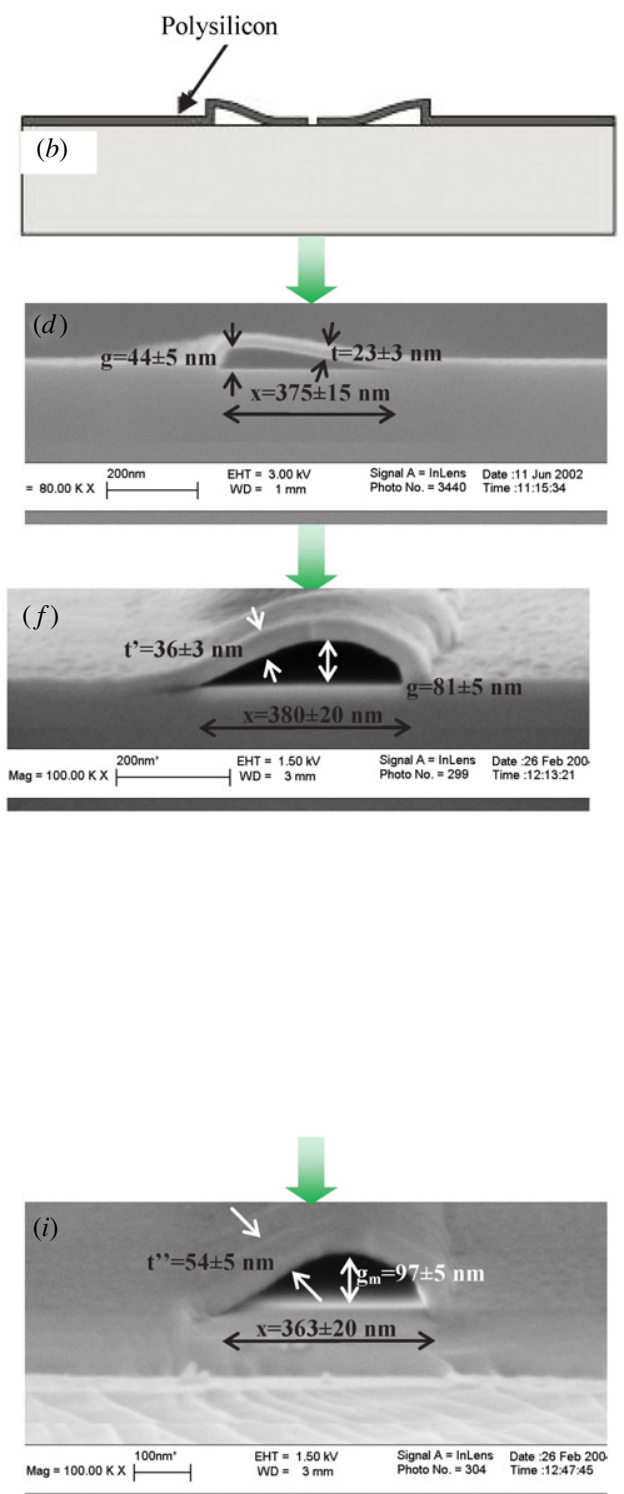

Figure 5. Cross-sectional SEM images of 2D nanochannels during processing with two etching possibilities of the sacrificial layer. Left images: remained silicon oxide and right images: completely etched silicon oxide. $(a),(b)$ Sketched finished process steps. $(c),(d)$ Nanochannels just after formation. $(e),(f)$ Nanochannels after partly oxidized the polysilicon capping layer. $(g)$ A nanochannel after the oxidized polysilicon capping layer was removed. $(h),(i)$ Nanochannels after completely oxidizing the polysilicon capping layer.

with various materials such as TI35, SU-8 (Micro Chemicals), unfortunately all resulting in cracking and peeling-off during the cryogenic DRIE step. Durimide 7500 series polyimide (Arch) successfully protected the fabricated structures during etching through the wafer, exhibiting the proper combination of thermal stability and mechanical toughness. Polyimide was coated (figure 1, step 9) on the front side containing nanochannel structures by a lithography procedure (step 9): dehydration $\left(5 \mathrm{~min}, 120{ }^{\circ} \mathrm{C}\right)$, spin coating $(20 \mathrm{~s}, 6000 \mathrm{rpm})$, soft-bake $\left(1 \mathrm{~min}, 95^{\circ} \mathrm{C}\right)$, flood exposure $(3 \mathrm{~s})$, post-bake in Leybold Heraeus vacuum oven $\left(1 \mathrm{~h}, 350^{\circ} \mathrm{C}, 2\right.$ mbar $)$. After a standard lithography step (10), inlet-port patterns were created on the back side of the wafer. Next, these patterns were transferred to the silicon substrate by DRIE etching (step 11) with an etch rate of $6 \mu \mathrm{m} \mathrm{min}{ }^{-1}$. The main etching parameters were a power of $600 \mathrm{~W}, 200 \mathrm{sccm} \mathrm{SF}_{6}$ flow, $1.0 \mathrm{sccm} \mathrm{O}$ flow, $-110{ }^{\circ} \mathrm{C}$ substrate temperature, $10 \mathrm{mTorr}$ process pressure and 65 min etching time. After etching, the polyimide layer was removed (step 12) by Piranha cleaning.

For the enclosed 2D nanochannels, DRIE was absolutely preferred over powder blasting. In powder blasting the highpressure flow of aluminum oxide will damage the fragile channels. Therefore, DRIE was used to create inlet ports for $2 \mathrm{D}$ nanochannels. The fabricated nanochannels were protected by a $500 \mathrm{~nm}$ thick silicon oxide layer deposited at $700{ }^{\circ} \mathrm{C}$ and 400 mTorr in $70 \mathrm{~min}$ (Tempress Systems Furnace) from TEOS (tetra-ethoxy-silane) and nitrogen (figure 3, step 12). This layer served as a protective layer during further processing and provided a transparent layer for optical observation as well. Inlet ports were integrated with the 

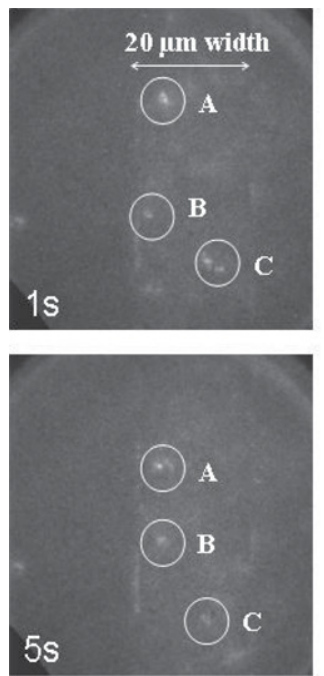
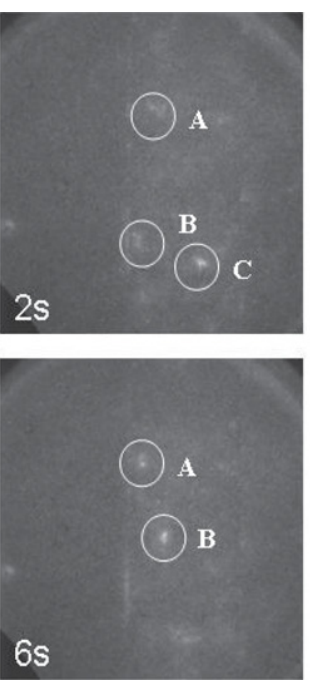
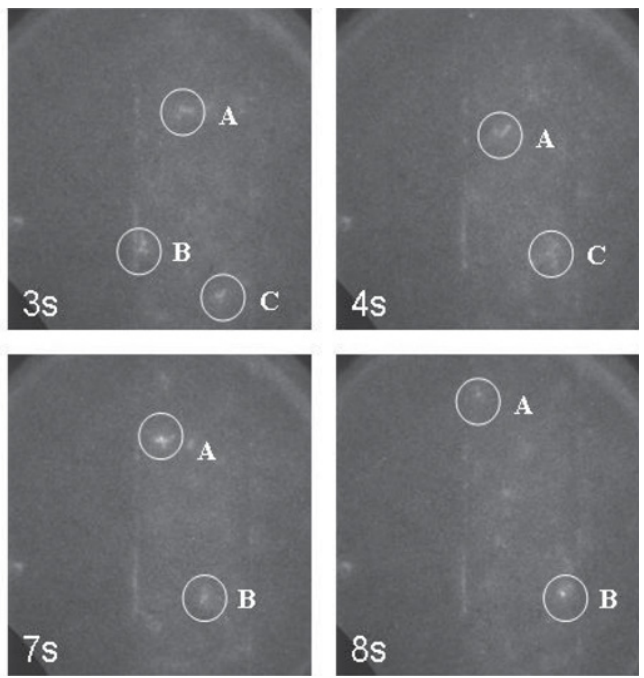

Figure 6. Blinking behavior of individual quantum dots visualized inside $1 \mathrm{D}$ nanochannels (150 nm height, $20 \mu \mathrm{m}$ width). Interfacing of the nanochannels is indicated by the while arrow. 'On' and 'off' states were observed in the quantum dot marked B (inside the white circle) whose fluorescence disappeared at the $4 \mathrm{~s}$ frame then reappeared in the $5 \mathrm{~s}$ frame. This behavior can be more clearly seen in Movie 1 (supporting material) stacks.iop.org/JMM/19/065017.
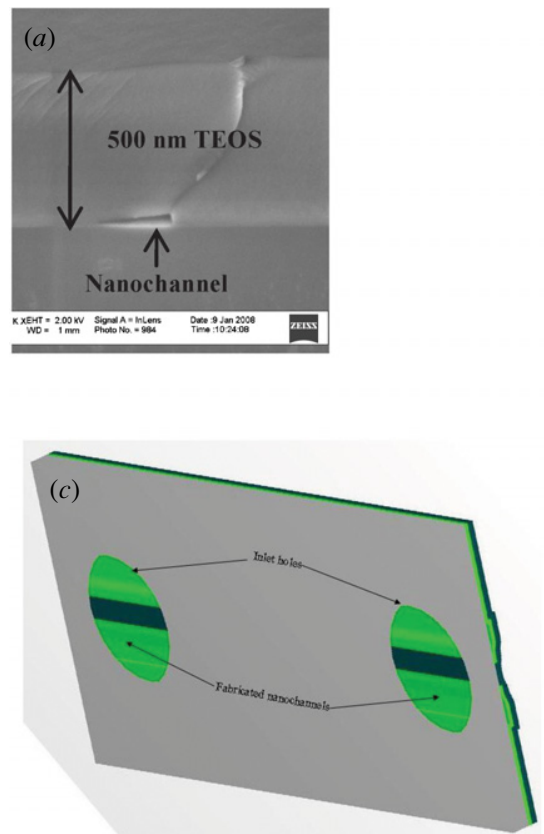
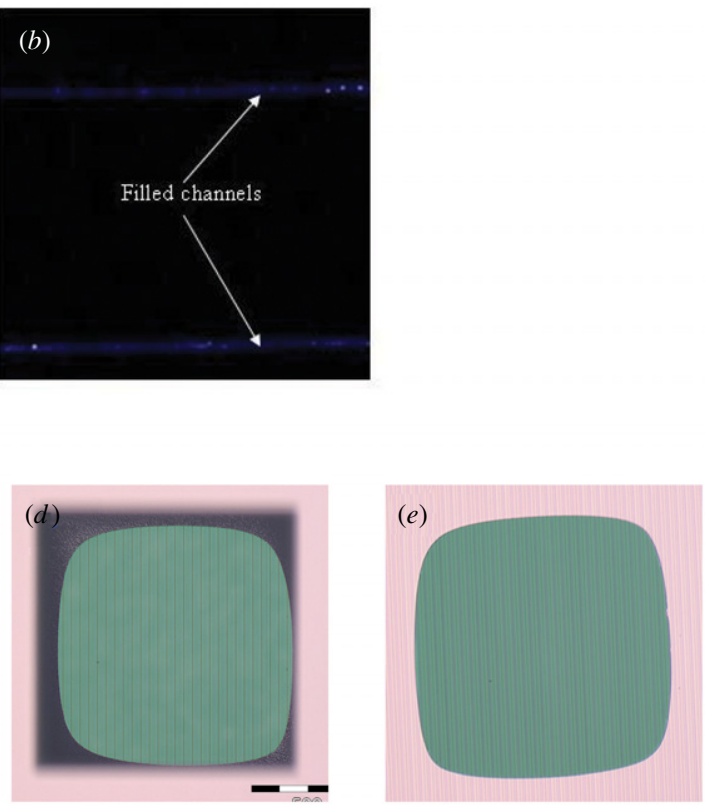

Figure 7. (a) A preserved nanochannel with $500 \mathrm{~nm}$ TEOS protection layer (b) A confocal fluorescence image of $4 \mu \mathrm{M}$ Alexa Fluor 488 solution in $50 \mathrm{~nm}$ height and $400 \mathrm{~nm}$ width 2D nanochannels. Image size is $43.4 \mu \mathrm{m} \times 43.4 \mu \mathrm{m}$. (c) An artist drawing of a 2D nanochannel device including inlet holes connected to channels for filling. $(d)$, (e) Optical microscope image of $0.9 \mathrm{~mm}$ diameter inlet holes, observed on top of the inlet hole and above the channels.

channels (figure $7(b)$ ) from the back side to avoid interference with the objective, a problem may occur when filling and observation takes place at the same side. A standard lithographic step (13) was applied to form patterns of inlet ports on the back side of the wafer and to coat the front side with a photoresist layer to protect the nanochannel structures. Next, the inlet-port patterns were transferred to the oxide layer by wet chemical etching in a BHF solution (10 min, step 14). Inlet ports were etched almost through the wafer by the DRIE etching (90 min, step 15) using the same parameters as presented for fabrication of the 1D nanochannels. Etching of the silicon was stopped on the stop layer introduced by the oxidation step (step 11) after fabrication of the channels. The stop layer was removed by RIE etching in $3 \mathrm{~min}$ and the channels were partly opened in the inlet-port area (step 16). The photoresist layers from both sides were removed (step 17) by oxygen plasma (20 min, Tepla $300 \mathrm{E}$ ). In a final step (18), thermal dry oxidation at $950{ }^{\circ} \mathrm{C}$ in 15 min the surfaces and 
side walls of the inlet ports were made hydrophilic to facilitate filling of the channels.

\section{Single-molecule mobility studies}

The $150 \mathrm{~nm}$ high 1D nanochannels (figure 2(c)) were used for observation of single quantum dots. The experiments were carried out on an upgraded inverted fluorescence microscope (Zeiss, Axiovert) (figure 2(a)) [52]. For excitation $488 \mathrm{~nm}$ argon laser light was focused into the nanochannels by using a $100 \times, 1.20 \mathrm{NA}$, water-immersion objective (Leica Planachromat). For detection of fluorescence intensities the microscope was equipped with an air-cooled intensified CCD camera (Pentamax, Princeton Instruments). Emission was detected with a $610 / 75 \mathrm{~nm}$ band pass filter and a notch filter was used to remove residual excitation intensities. Images of $50 \mu \mathrm{m} \times 50 \mu \mathrm{m}(512 \times 512$ pixels $)$ were recorded by using the WinSpec 32 program (Roper Scientific). Series of 40 sequential images were acquired at a rate of 5 frames per second (200 ms exposure time).

By capillary force the nanochannels were filled with a $12 \mathrm{nM}$ quantum dot solution (Evitag Fort Orange, type T2MP, carboxyl, CdSe/ZnS, $\sim 25 \mathrm{~nm}$ diameter, emission $600 \pm$ $10 \mathrm{~nm}$, Evident Technologies, NY). Imaging was started only after the equilibrium state was reached indicated by an absence of flow inside the channels. Quantum dots performed the well-known Brownian motion that a quantitative analysis is in progress. In the Brownian motion of single quantum dots, the average of its displacements tends to zero value which means there is no flow. Individual quantum dots could be visualized by virtue of the nano-confinement in the channels in combination with the high NA objective and the sensitive detection camera. The sequences of images (figure 6) identified the presence of individual quantum dots from the instantaneous appearance and disappearance of fluorescence, a demonstration of the well-known blinking behavior, characteristic for single fluorescent molecules. In every image of the series, dots could be recognized that were already present in the first image (dots A, B, C) and could be followed over several consecutive images (2 s-, 3 s-images); other dots disappeared (dot B in 4 s-image) and reappeared (dot $\mathrm{B}$ in 5 s-image) during imaging. For more detail, a movie of these sequence images is shown in the supporting information (Movie 1), stacks.iop.org/JMM/19/065017. Note that the number of quantum dots in the observation window is two orders of magnitude smaller than the calculated number corresponding to the original quantum-dot solution. Therefore, the observed concentration corresponds to $\sim 0.01 \mathrm{nM}$.

The performance of the 2D nanochannels was only tested regarding their filling capability. For visualization a homebuilt scanning confocal fluorescence microscope was used [53, 54]. Briefly, $488 \mathrm{~nm} \mathrm{Ar} / \mathrm{Kr}$ laser light was used for excitation in combination with a $63 \times, 1.20 \mathrm{NA}$ water immersion objective, a 525/50 nm band pass emission filter and an avalanche photodiode detector. Application of $4 \mu \mathrm{M}$ Alexa Fluor 488 (Molecular Probes, Eugene, OR) solution confirmed that filling of the $2 \mathrm{D}$ nanochannels indeed can properly be accomplished (figure $7(c)$ ). The concentration of $4 \mu \mathrm{M}$ was still three orders higher than the concentration required for the single-molecule level ${ }^{1}$. The observation of single fluorescent dye molecules inside 2D nanochannels is part of work in progress.

\section{Conclusions}

We fabricated 1D nanochannels using thin glass wafers as cover especially for observation with high NA lenses. Inlet ports for these 1D channels were constructed on silicon wafers for use in an inverted microscope configuration. 2D fragile nanochannels were successfully fabricated and made transparent for optical observation by oxidation then they were integrated to macro world by through-wafer inlet ports. Inlet/outlet ports integrated with the fabricated nanochannels were created using deep reactive ion etching at cryogenic temperature. The performance of the 1D nanochannels in single-molecule fluorescence detection was demonstrated from visualization of single quantum dots from a $12 \mathrm{nM}$ solution. These results indicate promising prospects for utilization of the nanochannels for various applications, such as e.g. single-molecule position tracking at physiologically relevant concentrations. Testing of the $2 \mathrm{D}$ nanochannels showed adequate performance in filling with a fluorescent solution.

\section{Acknowledgments}

The authors would like to thank the NanoNed program (flagship Nanofluidics) for financial support through the project 'Machining technologies for nanochannels and interfacing'.

\section{References}

[1] Lyon W A and Nie S 1997 Confinement and detection of single molecules in submicrometer channels Anal. Chem. 69 3400-5

[2] Wang Y M, Tegenfeldt J O, Reisner W, Riehn R, Guan X J, Guo L, Golding I, Cox E C, Sturm J and Austin R H 2005 Single-molecule studies of repressor-DNA interactions show long-range interactions Proc. Natl. Acad. Sci. USA 102 9796-801

[3] Verbridge S S, Edel J B, Stavis S M, Moran-Mirabal J M, Allen S D, Coates G and Craighead H G 2005 Suspended glass nanochannels coupled with microstructures for single molecule detection J. Appl. Phys. 97124317

[4] Nie S and Zare R N 1997 Optical detection of single molecules Annu. Rev. Biophys. Biomol. Struct. 26 567-96

[5] Levene M J, Korlach J, Turner S W, Foquet M, Craighead H G and Webb W W 2003 Zero-mode waveguides for single-molecule analysis at high concentrations Science 299 682-6

[6] Semwogerere D and Weeks E R 2005 Confocal microscopy Encyclopedia of Biomaterials and Biomedical Engineering (New York: Taylor Francis)

1 In a 2D channel volume $V=h \times w \times l$, where $h, w, l$ are the height, width and length of the channel; $h=50 \mathrm{~nm}, w=400 \mathrm{~nm}, l=50 \mu \mathrm{m}$. In order to have one molecule in this volume, concentration $C$ of solution should be $C=1 /(1000 \times V \times N)=1.7 \mathrm{nM}$. N is Avogadro number $(N=6.02 \times$ $\left.10^{23} / \mathrm{mole}\right)$. 
[7] Jin S, Huang P, Park J, Yoo J Y and Breuer K S 2003 Near-surface velocimetry using evanescent wave illumination ASME International Mechanical Engineering Congress \& Exposition (Washington, DC, 16-21 November 2003) IMECE 2003-44015

[8] Mooren O L, Erickson E S, Dickenson N E and Dunn R C 2006 Extending near-field scanning optical microscopy for biological studies J. Assoc. Lab. Autom. 11 268-72

[9] Persson F, Thamdrup L H, Mikkelsen M B L, Jaarlgard S E, Skafte-Pedersen P, Bruus H and Kristensen A 2007 Double thermal oxidation scheme for the fabrication of $\mathrm{SiO}_{2}$ nanochannels Nanotechnology 18245301

[10] Haneveld J, Tas N R, Brunets N, Jansen H V and Elwenspoek M 2008 Capillary filling of sub-10 nm nanochannels J. Appl. Phys. 104014309

[11] Mijatovic D, Eijkel J C T and Van Den Berg A 2005 Technologies for nanofluidic systems: top-down versus bottom-up- a review Lab Chip 5 492-500

[12] Alarie J P, Hmelo A B, Jacobson S C, Baddorf A P, Feldman L and Ramsey J M 2003 Fabrication and evaluation of 2D confined nanochannels 7 th Int. Conf. on miniaturized chemical and biochemical analysts systems (California, USA) pp 9-12

[13] Riehn R, Lu M, Wang Y M, Lim S F, Cox E C and Austin R H 2005 Restriction mapping in nanofluidic devices Proc. Natl. Acad. Sci. USA 102 10012-6

[14] Turner S W, Perez A M, Lopez A and Craighead H G 1998 Monolithic nanofluid sieving structures for DNA manipulation J. Vac. Sci. Technol. B 16 3835-40

[15] Hibara A, Saito T, Kim H B, Tokeshi M, Ooi T, Nakao M and Kitamori T 2002 Nanochannels on a fused-silica microchip and liquid properties investigation by time-resolved fluorescence measurements Anal. Chem. 74 6170-6

[16] Reisner W, Beech J P, Larsen N B, Flyvbjerg H, Kristensen A and Tegenfeldt J O 2007 Nanoconfinement-enhanced conformational response of single DNA molecules to changes in ionic environment Phys. Rev. Lett. 99058302

[17] Cao H, Yu Z, Wang J, Tegenfeldt J O, Austin R H, Chen E, Wu $\mathrm{W}$ and Chou S Y 2002 Fabrication of $10 \mathrm{~nm}$ enclosed nanofluidic channels Appl. Phys. Lett. 81 174-6

[18] Guo L J, Cheng X and Chou C F 2004 Fabrication of size-controllable nanofluidic channels by nanoimprinting and its application for DNA stretching Nano Lett. 4 69-73

[19] Liang X, Morton K J, Austin R H and Chou S Y 2007 Single sub-20 nm wide, centimeter-long nanofluidic channel fabricated by novel nanoimprint mold fabrication and direct imprinting Nano Lett. 7 3774-80

[20] Letant S E, van Buuren T W and Terminello L J 2004 Nanochannel arrays on silicon platforms by electrochemistry Nano Lett. 4 1705-7

[21] Wang M, Jing N, Su C B, Kameoka J, Chou C K, Hung M C and Chang K A 2006 Electrospinning of silica nanochannels for single molecule detection Appl. Phys. Lett. 88033106

[22] Sivanesan P, Okamoto K, English D, Lee C S and DeVoe D L 2005 Polymer nanochannels fabricated by thermomechanical deformation for single-molecule analysis Anal. Chem. 77 2252-8

[23] Huh D, Mills K L, Zhu X, Burns M A, Thouless M D and Takayama S 2007 Tuneable elastomeric nanochannels for nanofluidicmanipulation Nat. Mater. 6 424-8

[24] Lee C, Yang E H, Myung N V and George T 2003 A nanochannel fabrication technique without nanolithography Nano Lett. 3 1339-40

[25] Haneveld J, Jansen H, Berenschot E, Tas N and Elwenspoek M 2003 Wet anisotropic etching for fluidic 1D nanochannels J. Micromech. Microeng. 13 S62-6

[26] Pappaert K, Biesemans J, Clicq D, Vankrunkelsven S and Desmet G 2005 Measurements of diffusion coefficients in
1-D micro- and nanochannels using shear-driven flows $L a b$ Chip 5 1104-10

[27] Durand N F Y, Bertsch A, Todorova M and Renaud P 2007 Direct measurement of effective diffusion coefficients in nanochannels using steady-state dispersion effects Appl. Phys. Lett. 91203106

[28] Mannion J T, Reccius C H, Cross J D and Craighead H G 2006 Conformational analysis of single DNA molecules undergoing entropically induced motion in nanochannels Biophys. J. 90 4538-45

[29] Wu C, Jin Z, Wang H Q, Ma H and Wang Y 2007 Design and fabrication of a nanofluidic channel by selective thermal oxidation and etching back of silicon dioxide made on a silicon substrate J. Micromech. Microeng. 17 2393-7

[30] Han J and Craighead H G 1999 Entropic trapping and sieving of long DNA molecules in a nanofluidic channel J. Vac. Sci. Technol. A 17 2142-7

[31] Parikesit G O F, Markesteijn A P, Kutchoukov V G, Piciu O, Bossche A, Westerweel J, Garini Y and Young I T 2005 Electroosmotic flow analysis of a branched U-turn nanofluidic device Lab Chip 5 1067-74

[32] Stein D, Kruithof M and Dekker C 2004 Surface-charge-governed ion transport in nanofluidic channels Phys. Rev. Lett. 93035901

[33] Pennathur S and Santiago J G 2005 Electrokinetic transport in nanochannels. 1. Theory Anal. Chem. 77 6772-81

[34] Pennathur S and Santiago J G 2005 Electrokinetic transport in nanochannels. 2. Experiments Anal. Chem. 77 6782-9

[35] Pu Q, Yun J, Temkin H and Liu S 2004 Ion-enrichment and ion-depletion effect of nanochannel structures Nano Lett. 4 1099-103

[36] Mao P and Han J 2005 Fabrication and characterization of $20 \mathrm{~nm}$ planar nanofluidic channels by glass-glass and glass-silicon bonding Lab Chip 5 837-44

[37] van Delft K M, Eijkel J C T, Mijatovic D, Druzhinina T S, Rathgen H, Tas N R, Van Den Berg A and Mugele F 2007 Micromachined Fabry-Pérot interferometer with embedded nanochannels for nanoscale fluid dynamics Nano Lett. $7345-50$

[38] Cao H, Tegenfeldt J O, Austin R H and Chou S Y 2002 Gradient nanostructures for interfacing microfluidics and nanofluidics Appl. Phys. Lett. 81 3058-60

[39] O’Brien M J, Bisong P, Ista L K, Rabinovich E M, Garcia A L, Sibbett S S, Lopez G P and Brueck S R J 2003 Fabrication of an integrated nanofluidic chip using interferometric lithography J. Vac. Sci. Technol. B 21 2941-5

[40] Han A, Mondin G, Hegelbach N G, de Rooij N F and Staufer U 2006 Filling kinetics of liquids in nanochannels as narrow as $27 \mathrm{~nm}$ by capillary force $J$. Colloid Interface Sci. $293151-7$

[41] Cho Y H, Lee S W, Kim B J and Fujii T 2007 Fabrication of silicon dioxide submicron channels without nanolithography for single biomolecule detection Nanotechnology 18465303

[42] Ilic B, Czaplewski D, Zalalutdinov M, Schmidt B and Craighead H G 2002 Fabrication of flexible polymer tubes for micro and nanofluidic applications J. Vac. Sci. Technol. B 20 2459-65

[43] Tas N R, Berenschot J W, Mela P, Jansen H V, Elwenspoek M and Van Den Berg A 2002 2D-confined nanochannels fabricated by conventional micromachining Nano. Lett. 2 1031-2

[44] Eijkel J C T, Bomer J, Tas N R and Van Den Berg A 2004 1-D nanochannels fabricated in polyimide $L a b$. Chip. 4 161-3

[45] French P J 1996 Development of surface micromachining techniques compatible with on-chip electronics J. Micromech. Microeng 6 197-211 
[46] Haneveld J 2006 Nanochannel fabrication and characterization using bond micromachining PhD Thesis, University of Twente, The Netherlands

[47] Elwenspoek M and Jansen H V 1999 Silicon Micromachining (Cambridge: Cambridge University Press)

[48] Tas N, Sonnenberg T, Jansen H, Legtenberg R and Elwenspoek M 1996 Stiction in surface micromachining J. Micromech. Microeng. 6 385-97

[49] Backlund Y, Hermansson K and Smith L 1992 Bond-strength measurements related to silicon surface hydrophilicity J. Electrochem. Soc. 139 2299-301

[50] Chen X, Lin J, Xu S, Xin P and Wang L 2008 Oxidation of high area ratio silicon microchannels fabricated by electrochemical etching Proc. 3rd IEEE Int. Conf. on Nano/Micro Engineered and Molecular Systems (China)

[51] Polyakov A, Grob T, Hovenkamp R A, Kettelarij H J, Eidner I, de Samber M A, Bartek M and Burghartz J N 2004
Comparison of via-fabrication techniques for through-wafer electrical interconnect applications Electronic Components and Technology Conf. pp 1466-70

[52] Snijder-van As M I, Rieger B, Joosten B, Subramaniam V, Figdor C G and Kanger J S 2009 A hybrid total internal reflection fluorescence and optical tweezers microscope to study cell adhesion and membrane protein dynamics of single living cells J. Microsc. 233 84-92

[53] Kassies R, Lenferink A, Segers-Nolten I and Otto C 2005 Prism-based excitation wavelength selection for multicolor fluorescence coincidence measurements Appl. Opt. 44 893-7

[54] Segers-Nolten G M J, Wyman C, Wijgers N, Vermeulen W, Hoeijmakers J H J, Lenferink A T M, Greve J and Otto C 2002 Scanning confocal fluorescence microscopy for single molecule analysis of nucleotide excision repair complexes Nucleic Acids Res. 30 4720-7 